\title{
Hydraulic fracture initiation theory for a horizontal well in a coal seam
}

\author{
Hou Bing ${ }^{1 *}$, Chen Mian ${ }^{1}$, Wang Zheng ${ }^{2}$, Yuan Jianbo ${ }^{1}$ and Liu Ming ${ }^{1}$
}

\author{
${ }^{1}$ State Key Laboratory of Petroleum Resource and Prospecting, China University of Petroleum, Beijing 102249, China \\ ${ }^{2}$ Security Department, Tuha Oil Company, Shanshan, Xinjiang 838202, China
}

(C) China University of Petroleum (Beijing) and Springer-Verlag Berlin Heidelberg 2013

\begin{abstract}
A series of experiments were performed to determine rock mechanical parameters related to hydraulic fracturing of coal. The effect of confining pressure and pore pressure on the strength of coal was studied. Experimental results show that the coal seam in the study areas has a relatively low elastic modulus, high Poisson's ratio, high fragility and is easily broken and compressed. The coal seam is considered as a transversely isotropic medium, since the physical properties in the direction of bedding plane and orthogonal to the bedding plane vary markedly. Based on the generalized plane strain model, stress distribution for an arbitrarily orientated wellbore in the coal seam was determined. In a horizontal well, hydraulic fracturing was found to initiate in the coal seam mass due to tensile failure, or from cleats due to shear or tensile failure. For those coal seams with abundant natural cleats, hydraulic fracture initiation can be induced by any of these mechanisms. In this study, hydraulic fracture initiation criteria for a horizontal well in a coal seam were established.
\end{abstract}

Key words: Hydraulic fracturing, coal seam, transversely isotropic, fracture initiation, cleat, natural fracture

\section{Introduction}

Hydraulic fractures usually initiate in the direction of maximum crustal stress. The fracture initiation pressure can be determined from the crustal stress condition on the wellbore wall (Rice, 1968; Nordgren, 1972; Hossain et al, 1999; Bruno and Nakagawa, 1991; Whittaker et al, 1992; Zhang and Chen, 2010a; 2010b; 2010c). Most coal is naturally fractured, with closely spaced, regular, planar fractures that are collectively known as cleats. For coal seams with natural cleats (plane cleat \& tip cleat), fracture initiation becomes complicated since cleats have certain occurrence and geometric space distribution. Different alignments and trends of cleats, various crustal stresses and wellbore geometric configurations all contribute to differences in wellbore stress conditions, thus leading to various fracture initiation scenarios (Thomson, 1998; Zhou et al, 2008; 2010; Thiercelin, 2009; Jeffrey et al, 2009; Chen et al, 2010; Zhang and Chen, 2010a; 2010b; 2010c).

Generally coal seam gas reservoirs consist of sedimentary rocks with smooth laminar structures. Under normal conditions, the elastic modulus perpendicular to the bedding plane is slightly greater than that in the direction parallel to the bedding plane, and Poisson's ratio, as well as other

*Corresponding author. email: houbing9802@163.com

Received August 22, 2012 mechanical parameters, also vary between these two orientations. This lamellar rock has mechanical and physical properties that are quite similar in the direction parallel to the bedding plane and indeed they are often considered the same in practical calculations; nevertheless, these properties vary greatly between the transverse direction (parallel to the bedding plane) and the longitudinal direction (perpendicular to the bedding plane). Therefore, sedimentary rock, especially coal seams (with abundance plane cleats, tip cleats \& laminations), is very often considered as a transversely isotropic medium (Zhao and Chen, 2006; Akulich, 2008; Olson, 2008; Zhang and Chen, 2009; Jin et al, 2009; 2011).

So far this factor has not been thoroughly taken into consideration when designing coal seam fracturing in China. Based on experimental results, several researchers summarized the transverse isotropic properties of coal seam (Li, 1997; Zhang, 2009; Li et al, 2000; Zhang and Chen, 2010a). However, they did not take stress condition of adjacent rock into consideration nor propose a comprehensive theory of the initiation of hydraulic fracturing. Based on a theoretical approach and rock mechanical tests on coal seam material, this paper determines the stress distribution of adjacent rock in arbitrary directions. Hydraulic fracture initiation for a horizontal well in the coal seam mass due to tensile failure and, from cleats due to shear or tensile failure is discussed. For those coal seams with an abundance of natural cleats, hydraulic fracture initiation can be caused by 
any of these mechanisms. Hydraulic fracture initiation criteria for horizontal wells in coal seams are also established.

\section{Analysis of coal seam mechanical properties}

Determination of basic physical parameters of rocks is very useful in terms of analyzing hydraulic fracture propagation. The physical properties of rocks are obtained by laboratory or field tests. There is no doubt that mechanical parameters determined in the field are more accurate and realistic. But considering the high cost and uncertainties, some researchers prefer laboratory tests when determining these parameters. The original stress state of coal seam must be taken into account in laboratory tests. Researchers usually retrieve data such as well depth, confining pressure, pore pressure etc. from geological information before laboratory tests (Li, 1994).

The preparation of rock specimens is an important part

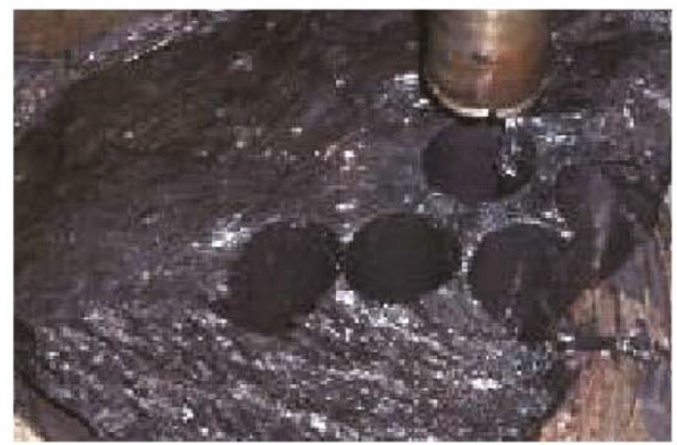

of these experiments. During the sampling process, we cored in both transverse and longitudinal directions, since the anisotropy of physical properties would be considered. The specific sampling process is shown in Fig. 1. Taking confining pressure and pore pressure into account, seven specimens were tested according to the above requirements.

A comparison of compression and tensile tests shows the anisotropy of mechanical properties (Table 1). On average, the elastic modulus of coal seams ranges from 4 to $5 \mathrm{GPa}$, which is smaller than that of normal sandstones. Poisson's ratio stays around $0.33-0.35$, which is significantly greater than that of other normal rock. These properties are determined by its special structure and evolution. The previous determination proved that the coal seam in the study areas has relatively low elastic modulus, high Poisson's ratio, high fragility and is easily broken and compressed. Moreover, the elastic modulus and Poisson's ratio in the longitudinal direction are greater than that in the transverse direction. A clear anisotropy also occurs in compression strength and tensile strength.
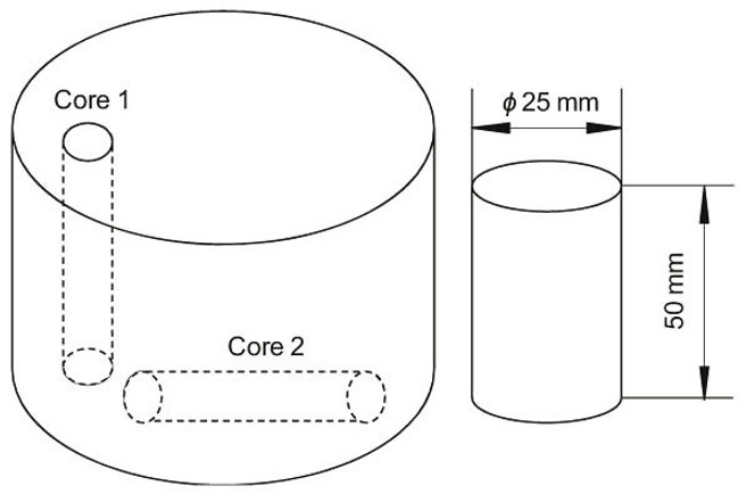

Fig. 1 Sampling process

Table 1 Comparison of anisotropy of mechanical properties of coal seam

\begin{tabular}{|c|c|c|c|c|c|c|c|c|}
\hline \multirow{2}{*}{ Sample } & \multicolumn{2}{|c|}{ Elastic modulus $E, \mathrm{GPa}$} & \multicolumn{2}{|c|}{ Poisson's ratio $v$} & \multicolumn{2}{|c|}{ Compression strength $\sigma, \mathrm{MPa}$} & \multicolumn{2}{|c|}{ Tensile strength $\sigma, \mathrm{MPa}$} \\
\hline & Vertical & Horizontal & Vertical & Horizontal & Vertical & Horizontal & Vertical & Horizontal \\
\hline $1^{\prime}$ & 6.500 & 0.300 & 0.50 & 0.10 & 19.6 & 13.2 & 0.25 & 0.80 \\
\hline $2^{\prime}$ & 2.797 & 0.391 & 0.43 & 0.14 & 13.6 & 6.80 & 0.27 & 0.75 \\
\hline $3^{\prime}$ & 1.718 & 0.696 & 0.37 & 0.21 & 12.4 & 4.70 & 0.12 & 0.27 \\
\hline $4^{\prime}$ & 3.192 & 0.416 & 0.35 & 0.11 & 9.80 & 4.40 & 0.25 & 0.54 \\
\hline $5^{\prime}$ & 1.437 & 0.579 & 0.41 & 0.27 & 10.7 & 6.40 & 0.26 & 0.46 \\
\hline
\end{tabular}

A coal gas reservoir is a sedimentary formation with a laminar structure. From a macroscopic point of view, its physical properties are anisotropic. A coal seam is generally considered as orthogonally anisotropic in terms of its mechanical response. Taking practical tests of mechanical properties into consideration, it can be further simplified as transversely isotropic. Consequently, considering a coal seam as tranversely isotropic $(k>1, n>1)$ is relatively close to the actual in-situ situation.

\section{Stress distribution in a horizontal wellbore in a coal seam}

The stress-strain relations of linear elastic materials is described by Hooke's Law. Thus the matrix form of stress distribution at any point can be expressed as:

$$
[\varepsilon]=[\boldsymbol{D}][\boldsymbol{\sigma}]
$$

where $[\sigma]=\left[\sigma_{x} \sigma_{y} \sigma_{z} \tau_{x y} \tau_{y z} \tau_{z x}\right]^{\mathrm{T}}$ is the stress array; $[\boldsymbol{\varepsilon}]=\left[\varepsilon_{x} \varepsilon_{y} \varepsilon_{z} \gamma_{x y} \gamma_{y z} \gamma_{z x}\right]^{\mathrm{T}}$ is the strain array; and $[\boldsymbol{D}]$ is a $6 \times 6$ elastic matrix. Any element in these matrices is constant, and can be determined from the elastic properties of the material. Du et al (1986) and Liu and Lu (1979) proved that the principal strain directions of tranversely isotropic materials are the same as that of the principal stress. Suppose the $y$ axis 
is the principal elastic direction that is normal to the bedding plane and the $x$ axis and $z$ axis are two other principal elastic directions, respectively. Lekhnitskii (1981) proved that for transversely isotropic materials, the independent elastic constants can be reduced from 21 to 5 . These constants are $a_{11}, a_{12}, a_{13}, a_{33}, a_{44}$. By representing $E, v, G$ as elastic modulus, Poisson's ratio and shear modulus in the $x z$ plane (parallel to the bedding plane) respectively, and $E^{\prime}, v^{\prime}, G^{\prime}$ as elastic constants in the direction of $y$ axis (normal to the bedding plane), the stress distribution in a horizontal wellbore in an actual coal gas formation can be sketched as shown in Fig. 2. Its wellbore axis is parallel to the coal seam bedding plane, which is the isotropic $x z$ plane. The stress-strain relations along the wellbore wall are shown in Eq. (2).

$$
\left[\begin{array}{l}
\varepsilon_{x} \\
\varepsilon_{y} \\
\varepsilon_{z} \\
\gamma_{y z} \\
\gamma_{x z} \\
\gamma_{x y}
\end{array}\right]=\left[\begin{array}{cccccc}
\frac{1}{E} & -\frac{v^{\prime}}{E^{\prime}} & -\frac{v}{E} & 0 & 0 & 0 \\
-\frac{v^{\prime}}{E^{\prime}} & \frac{1}{E^{\prime}} & -\frac{v^{\prime}}{E} & 0 & 0 & 0 \\
-\frac{v}{E} & -\frac{v^{\prime}}{E} & \frac{1}{E} & 0 & 0 & 0 \\
0 & 0 & 0 & \frac{1}{E}+\frac{1}{E^{\prime}}+2 \frac{v^{\prime}}{E^{\prime}} & 0 & 0 \\
0 & 0 & 0 & 0 & \frac{2(1+v)}{E} & 0 \\
0 & 0 & 0 & 0 & 0 & \frac{1}{E}+\frac{1}{E^{\prime}}+2 \frac{v^{\prime}}{E^{\prime}}
\end{array}\right]\left[\begin{array}{l}
\sigma_{x} \\
\sigma_{y} \\
\sigma_{z} \\
\tau_{y z} \\
\tau_{x z} \\
\tau_{x y}
\end{array}\right]
$$

where $E$ and $E^{\prime}$ denote the modulus of elasticity in the plane of isotropy and in the direction normal to the plane of isotropy, respectively, $\mathrm{MPa} ; v$ and $v^{\prime}$ denote Poisson's ratio in the plane of isotropy and Poisson's ratio in the direction normal to the plane of isotropy respectively. $\sigma_{x}, \sigma_{y}, \sigma_{z}, \tau_{x y}, \tau_{x z}, \tau_{y z}$ are far field stresses in the Cartesian coordinate system, MPa; $\varepsilon_{x}, \varepsilon_{y}, \varepsilon_{z}, \gamma_{y z}, \gamma_{x z}, \gamma_{x y}$ are far field strains in Cartesian coordinates; $\mathrm{MPa}$.
The degree of anisotropy $k$ and $n$ are defined to represent the difference of elastic parameters in the vertical and horizontal directions.

$$
\left\{\begin{array}{l}
k=\frac{E^{\prime}}{E} \\
n=\frac{v^{\prime}}{v}
\end{array}\right.
$$

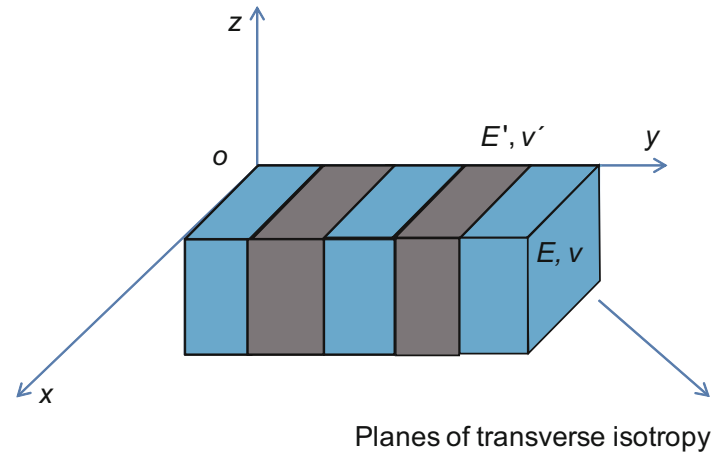

Fig. 2 Elastic parameters and stress analysis of borehole in a coal formation transversely isotropic in a plane striking parallel to the hole axis 
Based on the theory of elasticity, Ong (1994), Aadnoy (1987, 1989) and Amadei (1983, 1984, 1996) presented stress distribution equations for a wellbore in an anisotropic formation.

$$
\left\{\begin{array}{l}
\sigma_{x}=\sigma_{x, 0}+2 \operatorname{Re}\left[\mu_{1}^{2} \phi_{1}^{\prime}\left(z_{1}\right)+\mu_{2}^{2} \phi_{2}^{\prime}\left(z_{2}\right)+\lambda_{3} \mu_{3}^{2} \phi_{3}^{\prime}\left(z_{3}\right)\right] \\
\sigma_{y}=\sigma_{y, 0}+2 \operatorname{Re}\left[\phi_{1}^{\prime}\left(z_{1}\right)+\phi_{2}^{\prime}\left(z_{2}\right)+\lambda_{3} \phi_{3}^{\prime}\left(z_{3}\right)\right] \\
\tau_{x y}=\tau_{x y, 0}-2 \operatorname{Re}\left[\mu_{1} \phi_{1}^{\prime}\left(z_{1}\right)+\mu_{2} \phi_{2}^{\prime}\left(z_{2}\right)+\lambda_{3} \mu_{3} \phi_{3}^{\prime}\left(z_{3}\right)\right] \\
\tau_{x z}=\tau_{x z, 0}+2 \operatorname{Re}\left[\lambda_{1} \mu_{1} \phi_{1}^{\prime}\left(z_{1}\right)+\lambda_{2} \mu_{2} \phi_{2}^{\prime}\left(z_{2}\right)+\mu_{3} \phi_{3}^{\prime}\left(z_{3}\right)\right] \\
\tau_{y z}=\tau_{y z, 0}-2 \operatorname{Re}\left[\lambda_{1} \phi_{1}^{\prime}\left(z_{1}\right)+\lambda_{2} \phi_{2}^{\prime}\left(z_{2}\right)+\phi_{3}^{\prime}\left(z_{3}\right)\right] \\
\sigma_{z}=\sigma_{z, 0}-\frac{1}{a_{33}}\left(a_{31} \sigma_{x, \mathrm{~h}}+a_{32} \sigma_{y, \mathrm{~h}}+a_{34} \tau_{y z, \mathrm{~h}}+a_{35} \tau_{x z, \mathrm{~h}}+a_{36} \tau_{x y, \mathrm{~h}}\right)
\end{array}\right.
$$

where $R e$ denotes the real part of a complex variable; $a_{31}, a_{32}, a_{33}, a_{34}, a_{35}, a_{36}$ denote elastic constants.

For complex variables $z_{k}=x+\mu_{k} y \quad(k=1,2,3)$, analytic functions $\phi_{k}\left(z_{k}\right)$ can be obtained from boundary conditions. Lekhnistskii (1981) summarized the analytic functions at any given point. This paper mainly discusses the stress distribution of a horizontal wellbore in a coal seam, therefore, in the adjacent wellbore wall, we can get $x=a \cos \theta, y=a \sin \theta$. For a coal seam formation with apparent transverse isotropy, these functions can be further simplified as:

$$
\left\{\begin{array}{l}
\sigma_{x}=\sigma_{x, 0}+2 \operatorname{Re}\left[\mu_{1}^{2} \phi_{1}^{\prime}\left(z_{1}\right)+\mu_{2}^{2} \phi_{2}^{\prime}\left(z_{2}\right)\right] \\
\sigma_{y}=\sigma_{y, 0}+2 \operatorname{Re}\left[\phi_{1}^{\prime}\left(z_{1}\right)+\phi_{2}^{\prime}\left(z_{2}\right)\right] \\
\tau_{x y}=\tau_{x y, 0}-2 \operatorname{Re}\left[\mu_{1} \phi_{1}^{\prime}\left(z_{1}\right)+\mu_{2} \phi_{2}^{\prime}\left(z_{2}\right)\right] \\
\tau_{x z}=\tau_{x z, 0}+2 \operatorname{Re}\left[\mu_{3} \phi_{3}^{\prime}\left(z_{3}\right)\right] \\
\tau_{y z}=\tau_{y z, 0}-2 \operatorname{Re}\left[\phi_{3}^{\prime}\left(z_{3}\right)\right] \\
\sigma_{z}=\sigma_{z, 0}-\frac{1}{a_{33}}\left(a_{31} \sigma_{x, \mathrm{~h}}+a_{32} \sigma_{y, \mathrm{~h}}\right)
\end{array}\right.
$$

with

$$
\left\{\begin{array}{l}
\phi_{1}^{\prime}\left(z_{1}\right)=\frac{1}{2 \Delta\left(\mu_{1} \cos \theta-\sin \theta\right)}\left(E^{\prime} \mu_{2}-D^{\prime}\right) \\
\phi_{2}^{\prime}\left(z_{2}\right)=\frac{1}{2 \Delta\left(\mu_{2} \cos \theta-\sin \theta\right)}\left(D^{\prime}-E^{\prime} \mu_{1}\right) \\
\phi_{3}^{\prime}\left(z_{3}\right)=\frac{1}{2 \Delta\left(\mu_{3} \cos \theta-\sin \theta\right)}\left(F^{\prime} \mu_{2}-\mu_{1}\right)
\end{array}\right.
$$

For a horizontal well, its in-situ crustal stresses are as follows:

$$
\sigma_{x, 0}=\sigma_{\mathrm{H}} ; \sigma_{y, 0}=\sigma_{\mathrm{h}} ; \sigma_{z, 0}=\sigma_{\mathrm{v}} ; \tau_{y z, 0}=0 ; \tau_{x z, 0}=0 ; \tau_{x y, 0}=0
$$

where $\sigma_{\mathrm{H}}$ and $\sigma_{\mathrm{h}}$ denote the maximum horizontal stress and the minimum horizontal stress respectively; $\sigma_{v}$ is the overburden stress.

All these stress distribution equations are based on
Cartesian coordinates $(x, y, z)$. When $\theta=0$, the stress vectors are the same for both Cartesian and cylindrical coordinates. However, with an increase in $\theta$, the difference increases gradually. Therefore, it is necessary to convert these equations into cylindrical form $(r, \theta, z)$. Here is the transformation equation:

$$
\{\boldsymbol{\sigma}\}_{r \theta z}=\left[\boldsymbol{T}_{\sigma}\right]\{\boldsymbol{\sigma}\}_{x y z}
$$

where $\left[\boldsymbol{T}_{\boldsymbol{\sigma}}\right]$ is the transformation matrix.

Substituting this equation into stress distribution equations in Cartesian coordinates gives the stress distribution in cylindrical coordinates for a horizontal wellbore.

$$
\left\{\begin{array}{l}
\sigma_{r}=\cos ^{2} \theta \sigma_{x}+\sin ^{2} \theta \sigma_{y}+\sin 2 \theta \tau_{x y} \\
\sigma_{\theta}=\sin ^{2} \theta \sigma_{x}+\cos ^{2} \theta \sigma_{y}-\sin 2 \theta \tau_{x y} \\
\sigma_{z}=\sigma_{z} \\
\tau_{\theta z}=\cos \theta \tau_{y z}-\sin \theta \tau_{x z} \\
\tau_{r z}=\sin \theta \tau_{y z}+\cos \theta \tau_{x z} \\
\tau_{r \theta}=-0.5 \sin 2 \theta \sigma_{x}+0.5 \sin 2 \theta \sigma_{y}+\left(\cos ^{2} \theta-\sin ^{2} \theta\right) \tau_{x y}
\end{array}\right.
$$

where $\sigma_{r}$ denotes the radial stress on the wellbore wall, MPa; $\sigma_{\theta}$ denotes the tangential stress on the wellbore wall at an angular position $\theta$, MPa; $\sigma_{z}$ denotes the axial stress on the wellbore wall at an angular position $\theta, \mathrm{MPa} ; \tau_{r \theta}, \tau_{r z}, \tau_{\theta z}$ are the tangential stresses on the wellbore wall in cylindrical coordinates, MPa.

Substituting experimental data (Table 2) into this transversely isotropic model, the change of shear (with the difference of $k$ and $n$ ) along the wall can be easily analyzed. The results are shown in Figs. 3 and 4. Fig. 3 shows that when the angle changes, the degree of variation of shear stress with $k \& n$ is different. When $\theta=0$, the shear stress reaches its minimum value, and the tensile stress is greater than the tensile strength of coal seams, the borehole formation begins to fracture. On the contrary, the shear stress decreases with the increase in $k$, that is to say, a larger degree of surface anisotropy indicates easier collapse. However, Fig. 4 indicates that when $\theta=0$, the shear stress of anisotropy $(n>1)$ is less than that in isotropic formations $(n=1)$, nevertheless, the degree of Poisson's ratio anisotropy has little effect on shear stress. Therefore, the degree of anisotropy must be reasonably considered when fracturing coal formation.

Table 2 Input data

\begin{tabular}{ccc}
\hline \multirow{2}{*}{ Wellbore configuration } & $\begin{array}{c}\text { Liquid head, MPa } \\
\text { Well depth, } \mathrm{m}\end{array}$ & 0 \\
& $E, \mathrm{MPa}$ & 2000 \\
\hline \multirow{2}{*}{ Elastic parameters } & $E^{\prime}, \mathrm{MPa}$ & 5000 \\
& $v$ & 0.15 (variable) \\
& $v^{\prime}$ & 0.35 \\
\hline \multirow{2}{*}{ Crustal stress, $\mathrm{MPa}$} & $\sigma_{\mathrm{v}}$ & 15 \\
& $\sigma_{\mathrm{H} \max }$ & 11 \\
\hline
\end{tabular}




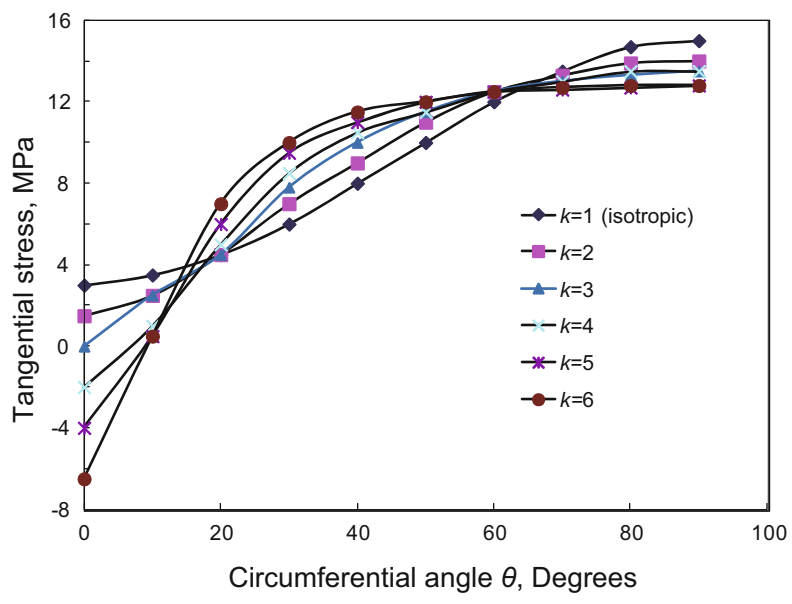

Fig. 3 Shear stress- $k$ relations

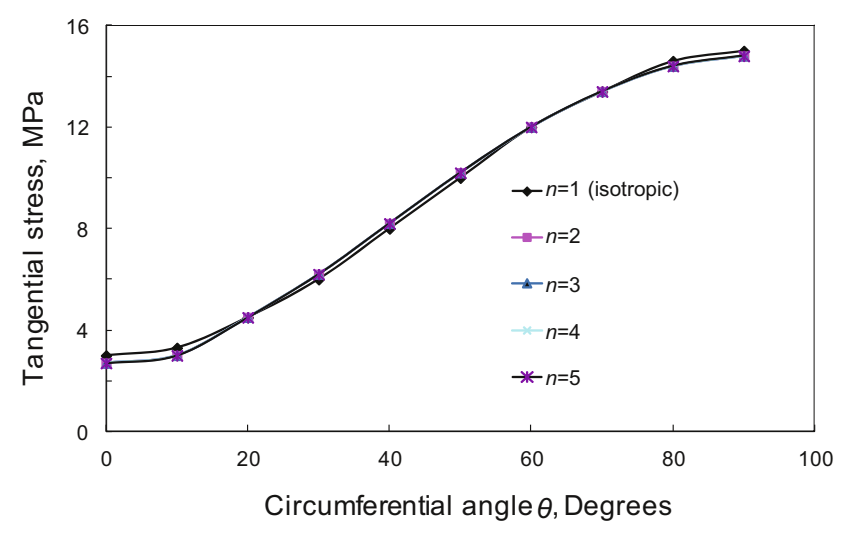

Fig. 4 Shear stress- $n$ relations

\section{Hydraulic fracture initiation criterion for a horizontal well in a coal seam}

\subsection{Tensile failure model of hydraulic fractures in coal seams}

The fracture pressure of coal formations is closely related to crustal stresses. High liquid head pressure leads to circumferential stress that exceeds the tensile strength of the coal seam, and thus results in fracture initiation and propagation in the formation.

$$
\sigma_{\theta}=-S_{\mathrm{t}}
$$

where $S_{\mathrm{t}}$ is the tensile strength of rock.

The circumferential stress acting on the wellbore wall $\sigma_{\theta}$ decreases with an increase in bottom hole pressure (BHP). When the BHP reaches a certain value, $\sigma_{\theta}$ becomes negative, which means that the tangential stress transfers from compression to tensile. The wellbore wall experiences fracturing as soon as the tangential stress is greater than the tensile stress of the coal seam, and fracturing occurs where $\sigma_{\theta}$ reaches its minimum value.

The position angle where the tensile failure occurs can be obtained with the following equation:

$$
\frac{\mathrm{d} \sigma_{\min }(\theta)}{\mathrm{d} \theta}=0
$$

By substituting this position angle $\theta$ into Eq. (10), the formation fracture pressure $p_{\mathrm{f}}^{\mathrm{b}}$ when the coal seam fails in tension can be obtained.

Horizontal fractures may occur when the coal formation is shallow enough. Under this circumstance, when the coal seam fractures horizontally, the vertical stress generated by fracturing liquid must be equal to or greater than the overburden pressure $\sigma_{\mathrm{v}}$ and its vertical tensile strength $S_{\mathrm{t}}^{\mathrm{v}}$.

Horizontal fracture occurs where:

$$
\sigma_{z}=-S_{\mathrm{t}}^{\mathrm{v}}
$$

\subsection{Shear failure model of hydraulic fractures along the coal seam cleat}

The principal stresses can be calculated using stress components acting on the wellbore wall which are obtained from the above methods. In cylindrical coordinates, the maximum, intermediate and minimum principle stresses can be expressed as follows.

$$
\begin{aligned}
& \sigma_{1}=\sigma_{r}=p_{\mathrm{w}} \\
& \sigma_{2}=\frac{\sigma_{z}+\sigma_{\theta}}{2}+\sqrt{\frac{\left(\sigma_{z}-\sigma_{\theta}\right)^{2}}{4}+\sigma_{\theta z}^{2}} \\
& \sigma_{3}=\frac{\sigma_{z}+\sigma_{\theta}}{2}-\sqrt{\frac{\left(\sigma_{z}-\sigma_{\theta}\right)^{2}}{4}+\sigma_{\theta z}^{2}}
\end{aligned}
$$

where $p_{\mathrm{w}}$ denotes the mud weight acting on the borehole wall; $\sigma_{1}, \sigma_{2}, \sigma_{3}$ are the maximum, intermediate, and minimum principle stresses in cylindrical coordinates, $\mathrm{MPa}$.

When existing natural fractures intersect each other, a weak plane model was once used to describe the shear failure of hydraulic fracture along natural fractures. Suppose these natural fractures exist in the main development zone, their alignments and trends are almost the same, thus using the weak plane model to describe the shear failure of hydraulic fractures along natural fractures is reasonable (Zhou et al, 2008; Valkó and Economides, 1994).

The weak plane failure criterion is:

$$
\sigma_{1}-\sigma_{3}=\frac{2\left(S_{\mathrm{w}}+\mu_{\mathrm{w}} \sigma_{3}\right)}{\left(1-\mu_{\mathrm{w}} \cot \beta_{2}\right) \sin 2 \beta_{2}}
$$

where $S_{\mathrm{w}}$ denotes the cohesive stress of the weak plane; $\mu_{\mathrm{w}}$ denotes weak plane coefficient of the internal friction; $\beta_{2}$ is the angle between the direction normal to the weak plane and the maximum principal stress.

When $\beta_{2}=\phi_{\mathrm{w}}$ or $\beta_{2}=\frac{\pi}{2}$, the weak plane would not slide. The weak plane slides only when: 


$$
\phi_{\mathrm{w}}<\beta_{2}<\frac{\pi}{2}
$$

Besides, $\sigma_{1}-\sigma_{3}$ must satisfy the weak plane failure criterion Eq. (16). $\phi_{\mathrm{w}}$ is the friction angle of the weak plane.

In fractured formations, $S_{\mathrm{w}}=0$, thus the shear failure criterion of hydraulic fractures along the natural fractures is:

$$
\sigma_{1}-\sigma_{3}=\frac{2 \mu_{\mathrm{w}} \sigma_{3}}{\left(1-\mu_{\mathrm{w}} \cot \beta_{2}\right) \sin 2 \beta_{2}}
$$

Consequently, the fracture pressure $p_{\mathrm{f}}^{\mathrm{z}}$ of the shear failure can be calculated.

\subsection{Tensile failure model of hydraulic fracture along coal seam cleat}

In earth coordinates, the alignment of natural fracture planes is north by east $T R$ degrees. $\beta_{2}$ is equal to the strata $\operatorname{dip} \theta_{\mathrm{DIP}} . \theta_{\mathrm{H}}$ is the azimuth of the maximum horizontal stress.

Suppose the natural fracture and wellbore wall intersect at $\theta$, then the normal stress of the fracture plane is:

$$
\sigma_{n}=\sigma_{z} l_{1}^{2}+\sigma_{\theta} l_{2}^{2}+\sigma_{r} l_{3}^{2}
$$

$$
\left\{\begin{array}{c}
l_{1}=\sin \theta_{\mathrm{DIP}} \\
l_{2}=-\sin \theta \cos \theta_{\mathrm{DIP}} \cos \left(T R-\theta_{\mathrm{H}}\right) \\
\quad+\cos \theta \cos \theta_{\mathrm{DIP}} \sin \left(T R-\theta_{\mathrm{H}}\right) \\
l_{3}=\cos \theta \cos \theta_{\mathrm{DIP}} \cos \left(T R-\theta_{\mathrm{H}}\right) \\
\quad+\sin \theta \cos \theta_{\mathrm{DIP}} \sin \left(T R-\theta_{\mathrm{H}}\right)
\end{array}\right.
$$

where $l_{1}, l_{2}$, and $l_{3}$ denote direction cosines of angles between the fracture plane normal direction and three principal stresses.

A tensile failure model of hydraulic fractures along the coal seam cleat can be expressed as:

$$
p_{\mathrm{f}}^{\mathrm{t}}=p_{\mathrm{w}} \geq \sigma_{n}
$$

where $p_{\mathrm{f}}^{\mathrm{t}}$ is the tensile failure pressure from cleats, MPa.

For those coal seams with abundant natural cleats, hydraulic fractures may initiate due to any of the following reasons: tensile failure, or from cleats due to shear or tensile failure. The mode of hydraulic fracture initiation and fracture pressure $p_{\mathrm{f}}$ are determined by:

$$
p_{\mathrm{f}}=\min \left\{p_{\mathrm{f}}^{\mathrm{b}}, p_{\mathrm{f}}^{\tau}, p_{\mathrm{f}}^{\mathrm{t}}\right\}
$$

where $p_{\mathrm{f}}^{\mathrm{b}}$ is the tensile failure pressure, $\mathrm{MPa} ; p_{\mathrm{f}}^{\tau}$ is the shear failure pressure from cleats, $\mathrm{MPa}$

If hydraulic fractures initiate in the coal seam mass, the initiation angle can be easily calculated.

\section{Conclusions}

Based on a series of rock mechanical experiments on samples from coal seams, the following conclusions can be drawn:
1) Confining pressure and pore pressure have a direct effect on the strength of a coal seam; the coal seam in the test area has a relatively low elastic modulus, high Poisson's ratio, high fragility and are easily broken and compressed. Its mechanical \& physical properties are markedly different in the directions parallel and normal to the bedding plane, therefore coal seams are often considered as transversely isotropic materials.

2) We consider a coal seam as transversely isotropic based on its mechanical characteristics. Based on the generalized plane strain model, the stress distribution for an arbitrarily orientated wellbore in the coal seam can be determined. The effect of the degree of anisotropy on the stress acting on the wellbore wall is further studied. The results show that when the angle varies, the degree of change in shear stress with the degree of anisotropy is different.

3) Hydraulic fracture initiation in the coal seam mass due to tensile failure, or from cleat due to shear or tensile failure for horizontal wells are also studied in this paper. For those coal seams with an abundance of natural cleats, hydraulic fracture may initiate due to any of above reasons. Hydraulic fracture initiation criteria for horizontal wells in the coal seam are established.

\section{Acknowledgements}

The authors are grateful for the financial support from the National Natural Science Foundation of China (No. 51204195, No. 51074171 and No. 51274216).

\section{References}

Aadnoy B S. Continuum Mechanics Analysis of the Stability of Inclined Boreholes in Anisotropic Rock Formations. Ph.D. Dissertation. The University of Trondheim. 1987

Aadnoy B S. Stresses around horizontal boreholes drilled in sedimentary rocks. Journal of Petroleum Science and Engineering. 1989. 2(4): 349-360

Akulich A V. Numerical simulation of hydraulic fracture crack propagation. Moscow University Mechanics Bulletin. 2008. 63(1): 6-12

Amadei B. Rock Anisotropy and the Theory of Stress Measurements (Lecture Notes in Engineering). Germany: Springer-Verlag. Berlin Heidelberg New York Tokyo. 1983. 45-70

Amadei B. In situ stress measurements in anisotropic rock. International Journal of Rock Mechanics and Mining Science \& Geomechanics Abstracts. 1984. 21(6): 327-338

Amadei B. Importance of anisotropy when estimating and measuring in situ stresses in rock. International Journal of Rock Mechanics and Mining Science \& Geomechanics Abstracts. 1996. 33(3): 293-325

Bruno M S and Nakagawa F M. Pore pressure influence on tensile fracture propagation in sedimentary rock. International Journal of Rock Mechanics and Mining Sciences \& Geomechanics Abstracts. 1991. 28(4): 261-273

Chen M, Jiang H, Zhang G Q, et al. The experimental investigation of fracture propagation behavior and fracture geometry in hydraulic fracturing through oriented perforations. Petroleum Science and Technology. 2010. 28(13): 1297-1306

Du Q H, Yu S T and Yao Z H. Theory of Elasticity. Science Press. Beijing. 1986 (in Chinese)

Hossain M M, Rahman M K and Rahman S S. A comprehensive monograph for hydraulic fracture initiation from deviated wellbores 
under arbitrary stress regimes. Asia Pacific Oil and Gas Conference and Exhibition, 20-22 April 1999, Jakarta, Indonesia (SPE 54360)

Jeffrey R G, Zhang X and Thiercelin M. Hydraulic fracture offsetting in naturally fractured reservoirs: Quantifying a long-recognized process. SPE Hydraulic Fracturing Technology Conference, 19-21 January 2009, The Woodlands, Texas (SPE 119351)

Jin Y, Qi Z L, Chen M, et al. Time-sensitivity of the Kaiser effect of acoustic emission in limestone and its application to measurements of in-situ stress. Petroleum Science. 2009. 6(2): 176-180

Jin Y, Yuan J B, Chen M, et al. Determination of rock fracture toughness $K_{\| \mathrm{C}}$ and its relationship with tensile strength. Rock Mechanics and Rock Engineering. 2011. 44: 621-627

Lekhnitskii S G. Theory of Elasticity of an Anisotropic Body. Moscow: Mir Publishers. 1981

Li T L. Preliminary research on development of cracks in coal seams by hydraulic fracture. Earth Science- Journal of China University of Geosciences. 1994. 19(4): 537-545 (in Chinese)

Li T L. Analysis of coalbed hydraulic fracturing mechanism. Natural Gas Industry. 1997. 17(4): 53-56 (in Chinese)

Li Z G, Fu S L, Wu X M, et al. Research on mechanical property tests and mechanism of hydraulic fracture of gas well in coal beds. Petroleum Drilling Techniques. 2000. 28(3): 10-13 (in Chinese)

Liu B C and Lu H S. Elastic Mechanics. Metallurgical Industry Press. Beijing. 1979 (in Chinese)

Nordgren R. Propagation of a vertical hydraulic fracture. SPE Journal. 1972. 12(4): 306-314

Olson J E. Multi-fracture propagation modeling: Applications to hydraulic fracturing in shales and tight gas sands. The 42nd US Rock Mechanics Symposium (USRMS), 29 June - 2 July 2008, San Francisco, CA

Ong S H. Borehole Stability. Ph.D. Dissertation. University of Oklahoma. 1994. Norman, Oklahoma

Rice J R. Mathematical analysis in the mechanics of fracture. In: Fracture: An Advanced Treatise (Edited by Liebowitz H). Academic Press, New York. 1968. 191-311

Thiercelin M. Hydraulic fracture propagation in discontinuous media.
International Conference on Rock Joints and Jointed Rock Masses, 7-8 January 2009, Tucson, Arizona

Thomson S. The role of directional drilling for safety in coal mining. Proceedings of the 11th Turkish Coal Congress, 10-12 June 1998, Bartin-Amasra, Turkey

Valkó P and Economides M J. Propagation of hydraulically induced fractures: A continuum damage mechanics approach. International Journal of Rock Mechanics and Mining Sciences \& Geomechanics Abstracts. 1994. 31(3): 221-229

Whittaker B N, Singh R N and Sun G. Rock Fracture MechanicsPrinciples Design and Applications. Amsterdam: Elsevier, New York. 1992

Zhang G Q. Rock failure with weak planes by self-locking concept. International Journal of Rock Mechanics and Mining Sciences. 2009. 46(6): 974-982

Zhang G Q and Chen M. Study of the optimal timing for refracturing. Petroleum Science and Technology. 2009. 27(10): 969-983

Zhang G Q and Chen M. Dynamic fracture propagation in hydraulic refracturing. Journal of Petroleum Science and Engineering. 2010a. 70(3-4): 266-272

Zhang G Q and Chen M. Study of damage mechanism by production testing after acid fracturing of carbonate reservoir. Petroleum Science and Technology. 2010b. 28(2): 125-134

Zhang G Q and Chen M. The relationship between the production rate and initiation location of new fractures in a refractured well. Petroleum Science and Technology. 2010c. 28(7): 655-666

Zhao Z F and Chen M. Relationship between rock fracture toughness and physical properties. Petroleum Science. 2006. 3(1): 56-60

Zhou J, Chen M, Jin Y, et al. Analysis of fracture propagation behavior and fracture geometry using a tri-axial fracturing system in naturally fractured reservoirs. International Journal of Rock Mechanics and Mining Sciences. 2008. 45(7): 1143-1152

Zhou J, Chen M, Jin Y, et al. Experimental investigation of hydraulic fracturing in random naturally fractured blocks. International Journal of Rock Mechanics and Mining Sciences. 2010. 47(7): 1193-1199

(Edited by Sun Yanhua) 